\title{
New microsatellite DNA markers to resolve population structure of the convict surgeonfish, Acanthurus triostegus, and cross-species amplifications on thirteen other Acanthuridae
}

\author{
Grulois Daphné ${ }^{1}$, Hogan Raissa Iris ${ }^{1,2}$, Paygambar Stéphane ${ }^{1}$, Planes Serge ${ }^{3,4}$, \\ Fauvelot Cécile ${ }^{1,4,5,{ }^{*}}$
}

\begin{abstract}
1 UMR250 ENTROPIE, BPA5, Institut de Recherche pour le Développement (IRD), 101 Promenade
Roger Laroque, 98848, Noumea cedex, New Caledonia

2 Ryan Institute, National University of Ireland, Galway, Ireland

3 USR 3278 CRIOBE, PSL Research UniversityEPHE-UPVD-CNRS, Université de Perpignan, 52

Avenue Paul Alduy, 66860, Perpignan Cedex, France

${ }^{4}$ Laboratoire d'Excellence CORAIL, CRIOBE-USR $3277^{8}$ PSL Université Paris: EPHE-CNRS-UPVD,

Paris, France

${ }^{5}$ Laboratoire d'Océanographie de Villefranche, Sorbonne Université, UMR ENTROPIE, CNRS,

Villefranche-sur-Mer, Paris, France
\end{abstract}

* Corresponding author : Cécile Fauvelot, email address : cecile.fauvelot@ird.fr

\begin{abstract}
:
Microsatellites are widely used to investigate connectivity and parentage in marine organisms. Despite surgeonfish (Acanthuridae) being dominant members of most reef fish assemblages and having an ecological key role in coral reef ecosystems, there is limited information describing the scale at which populations are connected and very few microsatellite markers have been screened. Here, we developed fourteen microsatellite markers for the convict surgeonfishAcanthurus triosteguswith the aim to infer its genetic connectivity throughout its distribution range. Genetic diversity and variability was tested over 152 fishes sampled from four locations across the Indo-Pacific: Mayotte (Western Indian Ocean), Papua New Guinea and New Caledonia (Southwestern Pacific Ocean), and Moorea (French Polynesia). Over all locations, the number of alleles per locus varied from 5 to 24 per locus, and expected heterozygosities ranged from 0.468 to 0.941 . Significant deviations from Hardy-Weinberg equilibrium were detected for two loci in two to three locations and were attributed to the presence of null alleles. These markers revealed for the first time a strong and significant distinctiveness between Indian Ocean and Pacific OceanA. triosteguspopulations. We further conducted cross-species amplification tests in 13 Pacific congener species to investigate the possible use of these microsatellites in other Acanthuridae species. The phylogenetic placement of A. triostegusbranching off from the clade containing nearly allAcanthurus + Ctenochaetusspecies likely explain the rather good transferability of these microsatellite markers towards other Acanthuridae species. This suggests that this fourteen new microsatellite loci will be helpful
\end{abstract}


tools not only for inferring population structure of various surgeonfish but also to clarify systematic relationships among Acanthuridae.

Keywords : Coral reef fish, Microsatellites, Connectivity, Indo-pacific, Genetic structure, Surgeonfish 


\section{Introduction}

Acanthuridae (surgeonfishes, tangs and unicornfishes) are dominant fish taxa in most coral reefs, with an ecological key role in preventing shifts from coral- to algal-dominance following disturbance [1]. Yet, Acanthuridae are under increasing pressure: they are heavily targeted by artisanal fishing (several unicornfish are highly prized in tropical Indo-Pacific fisheries) and/or as ornamental species, being in the top 10 of the most-frequently exported aquarium fish in trade [2-4]. Despite its importance above, and although it is one of the most widespread coral reef fish family in coral reefs, it is one of the least studied in terms of population genetic structure. Only a few studies have investigated phylogeographical patterns and/or population genetic connectivity in these fishes, and for the majority, the genetic variation was inferred using mitochondrial DNA (mtDNA) markers [5-13]. Only a limited number of studies used nuclear microsatellite markers, despite their high resolving power for detecting divergence $[14,15]$.

Currently available Acanthuridae microsatellite makers were designed from only 3 out of the 84 species of Acanthuridae: one tang, one unicornfish and one surgeonfish. The genetic structure of the yellow tang Zebrasoma flavescens was investigated throughout its Pacific distribution range using 23 specific microsatellites loci [16]. Compared to previously used mtDNA markers, microsatellite markers provided finer estimates of the spatial subdivision of the Hawaiian population [17] and allowed to infer small scale larval dispersal through genetic parentage analyses in yellow tang off the Island of Hawai'i [18]. In the unicornfish Naso unicornis, the genetic relatedness among recruits was inferred using 15 specially developed microsatellites loci [19], revealing a broad-scale genetic connectivity across the southern Marianas Islands [20]. Lastly, ten microsatellite markers developed from hybrids of Acanthurus nigricans x A. leucosternon [21] were specifically used to study introgression patterns among four species of Acanthurids and investigate evolutionary processes leading to hybridization among closely related species [22]. These microsatellites were latter used in two related studies exploring the genetic structure and connectivity of two species of Acanthurids at the Eastern African region scale, A. leucosternon and A. triostegus, revealing homogeneous panmictic populations at this spatial scale for the two species [23, 24]. 
The convict surgeonfish A. triostegus is found throughout the tropical Indo-Pacific, from South African to Baja Californian reefs. The genetic population structure of A. triostegus across its entire range, using either allozymes or mtDNA sequences $[13,25]$ revealed globally congruent results: 1) a marked genetic differentiation of populations from the Hawaiian archipelago, suggesting biogeographic vicariance as an evolutionary process leading to the differentiation of the A. triostegus populations in this archipelago; and 2) a significant correlation between genetic differentiation and geographic distance among the remaining populations, indicative of an isolation by distance.

Significant genetic differentiation between the Indian and Pacific Ocean populations was found, though only $8.3 \%$ of all pairwise comparisons were significant [13]. In addition, no significant differentiation was found across the East Pacific Barrier [6], suggesting a great dispersal potential of this species. Nevertheless, one discrepancy among nuclear and mitochondrial markers remains with the Marquesas population being as much differentiated than the Hawaiian archipelago from the rest of the Pacific populations based on allozymes [25] but not based on mtDNA sequences $[6,12,13]$. This incongruity calls for additional type of markers to be used.

Here we report the development of fourteen microsatellite markers whose power to detect genetic subdivision are tested across four populations sampled across the distribution range of the species. In addition we tested cross-amplification on thirteen congeners to investigate their potential to be used more widely within the Acanthuridae family.

\section{Material and Methods}

\section{Microsatellite library development and primer selection}

Approximately $20 \mathrm{ng}$ of genomic DNA was isolated from muscle tissue of one A. triostegus sampled in Moorea, French Polynesia and preserved in $80 \%$ EtOH. Size-selected fragments from genomic DNA were enriched for SSR content by using magnetic streptavidin beads and biotin-labeled CT and GT repeat oligonucleotides. The SSR-enriched library was analyzed on a Roche 454 platform using the GS FLX Titanium reagents. A total of 21'986 reads had an average length of 128 base pairs. Of these, 3'482 contained a microsatellite insert with a tetra- or a trinucleotide of at least 6 repeat units or a dinucleotide of at least 10 repeat units. Suitable primer design was possible in 1'042 reads and 32 
loci were tested for PCR amplification and polymorphism on 8 individuals sampled in Moorea using the method fully detailed in Schuelke [26]. Genomic DNA was isolated from fin clips using Gentra Puregene Tissue Kit (Qiagen). Forward primers were labelled with a fluorochrome (6-FAM) by adding a universal 18-bp M13 tail at their 5'-end (5'-TGTAAAACGACGGCCAGT-3'). PCRs were performed in a total volume of $10 \mu \mathrm{L}$ with $1 \mathrm{X}$ Qiagen buffer stock, $0.04 \mu \mathrm{M}$ of forward primer tagged with the M13 tail, $0.16 \mu \mathrm{M}$ of reverse primer, $0.16 \mu \mathrm{M}$ of fluorescent dyed M13 primer, $0.5 \mathrm{U}$ of Hotstar Taq and $10 \mathrm{ng}$ of genomic DNA. The following thermocycling program was used: $95^{\circ} \mathrm{C}$ for 15 $\min +30 \times\left(95^{\circ} \mathrm{C}\right.$ for $30 \mathrm{~s}, 56^{\circ} \mathrm{C}$ for $45 \mathrm{~s}, 72^{\circ} \mathrm{C}$ for $\left.45 \mathrm{~s}\right)+8 \times\left(95^{\circ} \mathrm{C}\right.$ for $30 \mathrm{~s}, 53^{\circ} \mathrm{C}$ for $45 \mathrm{~s}, 72^{\circ} \mathrm{C}$ for $45 \mathrm{~s})+72^{\circ} \mathrm{C}$ for 30 min. PCR products were genotyped using an ABI3730 sequencer (Applied Biosystems) with the GS-LIZ-500 Size Standard (Applied Biosystems). Microsatellite peaks in the electropherograms were examined and the most promising 14 microsatellite loci were selected for further genotyping and analysis based on the fact that (1) primer pairs amplified fragments in all eight individuals, (2) the number of different alleles was higher than 25\% (i.e. at least 4 out of the 16 possible amplified alleles), and (3) they did not amplify multiple fragments (Table 1).

\section{Polymorphism and cross - amplification testing}

The final set of 14 microsatellite loci selected were further characterized by genotyping individuals sampled in four locations: three islands of the Pacific Ocean-Moorea in French Polynesia, Grande Terre in New Caledonia, and Loloata Island in Papua New Guinea and one island in the Western Indian Ocean, Mayotte (Table 1). Genomic DNA was isolated from fin clips using Gentra Puregene Tissue Kit (Qiagen). PCR reactions were performed using Type-It Microsatellite (Qiagen) in two distinct multiplexes of $5 \mu$ final volume containing 1X Master Mix, 0.5X of Q-solution, $0.1 \mu \mathrm{M}$ of each primer (fluorescent-labeled forward primer 6-FAM, PET, NED or VIC) and 50 to $150 \mathrm{ng}$ of DNA template (Table 1). All PCRs were conducted in GeneAMP PCR System 9700 (Applied Biosystems) and a unique program was used to amplify the two multiplexes, consisting of $5 \mathrm{~min}$ at $94^{\circ} \mathrm{C}, 28$ cycles at $95^{\circ} \mathrm{C}$ for $30 \mathrm{~s}, 58^{\circ} \mathrm{C}$ for $90 \mathrm{~s}$ and $72^{\circ} \mathrm{C}$ for $30 \mathrm{~s}$, and a final step at $60^{\circ} \mathrm{C}$ for $30 \mathrm{~min}$. 
Biosystems) with GS-500-LIZ (Applied Biosystems). Alleles were sized using GeneMapper®

(Applied Biosystems).

Cross-species amplification was tested on 13 species of 3 genus of Acanthuridae sampled in New

Caledonia (A. albipectoralis, A. blochii, A. dussmieri, A. nigricauda, A. nigrofuscus, A. olivaceus) and in Moorea (A. nigricans, A. pyroferus, A. xanteptorus, Ctenochaetus birotatus, C. flavicauda, C. striatus and Naso lituratus). PCR were conducted in the exact same conditions as described above. We will then only report the number of loci that amplified, the number of alleles observed for each loci and the size range of the alleles.

\section{Data analysis for Acanthurus triostegus}

Genetic diversity within samples was estimated at the fourteen loci from the observed $\left(H_{\mathrm{O}}\right)$ and expected $\left(H_{\mathrm{E}}\right)$ heterozygosities in GENETIX 4.05 [27]. Deviations from Hardy-Weinberg (HW) equilibrium were estimated for each loci using Weir \& Cockerham's [28] estimator of the $F_{\text {IS }}$ inbreeding coefficient, and departures from HW expectations were tested using the probability test in GENEPOP v 4.7.5 on the web $[29,30]$ with default Markov chain parameters and applying a standard Bonferroni correction [31]. Genotypic linkage disequilibrium among loci was tested using GENEPOP for each sample. MICRO-CHECKER 2.2.3 [32] was used to screen for the presence of null alleles, scoring error due to stuttering and large allele dropout. multilocus estimator of $F_{\mathrm{ST}}\left({ }^{\wedge} \theta\right)$ in GENETIX. The genic differentiation for each population pair was tested using the exact G test of GENEPOP. The sequential Bonferroni correction [31] was applied for each test. The population structure was further examined using a Discriminant Analysis of Principal Components (DAPC) procedure described by Jombart et al. [33] to identify the number of genetically distinct clusters $(\mathrm{K})$ present in the dataset. We chose this method as it does not make any assumption about HWE or linkage equilibrium and transforms genotypes using PCA as a prior step to a discriminant analysis. DAPC was run using the adegenet package [34] for R (R Development Core Team 2016). For comparison, we also performed a Bayesian analysis using STRUCTURE 2.3.4 [35] to determine the most likely number of genetically distinct clusters $(\mathrm{K})$ among the 156 genotyped 
individuals. Conditions were set to 500000 chain length after a burn-in of 50 000, assuming admixture and using the location prior option. Percentage of membership of each individual to each cluster $(K=1$ to $\mathrm{K}=5$ ) were obtained pooling the results of 10 independent runs with CLUMPP 1.1.2 [36] and were graphically displayed using DISTRUCT [37].

\section{Results and discussion}

\section{Characterization of microsatellite loci}

Sequences of the 14 selected loci are available on GenBank with accession numbers from MT876122MT876135 and primer sequences are presented in Table 1. Within the sample from Moorea (the original location of the fish used to isolate all the microsatellite loci), between 5 and 22 alleles (mean $=14.14$ ) were observed per locus, very similar to what found in Naso unicornis [19] and Zebrasoma flavescens [16] microsatellite loci. Expected heterozygosity values ranged from 0.692 to $0.925(0.840$ over all loci) (Table 1). No significant genotypic linkage disequilibrium among loci was found but significant deviation from HW expectations was observed in a single locus, Acatri_13915 $\left(F_{\text {IS }}=0.523\right.$, $P<0.0001)$. This excess of homozygotes was attributed to the presence of null alleles. For Acatri_09917, null alleles were also found to be present, but with no significant departure from HW expectations.

Within the three other samples (New Caledonia, Loloata Isl. and Mayotte), the genetic diversity was similar, with a number of alleles per locus between 7 and 24 and mean number of alleles ranging from 11.21 in New Caledonia to 15.07 in Mayotte (Table 1). Expected heterozygosity values ranged from 0.468 to 0.941 (with mean values over all loci ranging from 0.822 in Mayotte to 0.850 in Loloata Isl.). Significant deviations from HW expectations were observed for Acatri_13915 $\left(F_{\mathrm{IS}}=0.237, P<0.0001\right)$ in Mayotte, and for Acatri_09917 in Mayotte $\left(F_{\mathrm{IS}}=0.173, P<0.0001\right)$, Loloata Isl. $\left(F_{\mathrm{IS}}=0.210, P\right.$ $<0.0001)$ and New Caledonia $\left(F_{\mathrm{IS}}=0.382, P<0.0001\right)$. In all these cases, the deficits of homozygotes were attributed to the occurrence of null alleles.

\section{Detection of significant genetic structure}


Pairwise genetic divergence among samples were significant for all pairwise comparisons except between New Caledonia and Loloata island, the closest sampled populations. Genetic differentiation estimates ranged from 0.00097 (exact $P$-value $=0.087$ ) between New Caledonia and Loloata island to $0.03786\left(P<10^{-11}\right)$ between Mayotte and Loloata Isl.

The strong distinctiveness of the Indian Ocean sample, Mayotte, was further confirmed by the two different clustering approaches. The STRUCTURE analysis revealed that the best partition was obtained for $\mathrm{K}=2$, with all Indian Ocean individuals (i.e. Mayotte) belonging to cluster 1, and all Pacific Ocean individuals (i.e. Loloata Isl., New Caledonia and Moorea) belonging to cluster 2 (Fig. 1a). The results of DAPC (Fig. 1b and c) are largely consistent with those of the Bayesian analysis showing that all analysed individuals are separated in two distinct genetic clusters, one cluster being represented by most of the Indian Ocean individuals, and the second, by most of the Pacific Ocean individuals. The occurrence of Pacific Ocean individuals belonging to the Indian Ocean cluster (Fig. 1c) may represent directional gene flow from the Pacific Ocean to the Indian Ocean and/or homoplasy.

\section{Cross-species amplifications}

Cross-species amplification tests (Table 2) resulted in 10 loci amplifying in A. nigricans (Anig), 8 loci amplifying in A. pyroferus (Apyr), C. striatus (Cstri) and C. birotatus (Cbir), 7 loci amplifying in A. xanteptorus (Axan) and A. olivaceus (Aoli), 6 loci amplifying in A. albipectoralis (Aalb), A. nigricauda (Anic), A. nigrofuscus (Anif) and Ctenochaetus flavicauda (Cfla), 5 loci amplifying in A. dussmieri (Adus), and 4 loci amplifying in Naso lituratus (Nlit) and A. blochii (Ablo), though lower annealing temperatures may be tested to improve these successes. The rather good transferability of A. triostegus microsatellite markers towards other Acanthuridae species considered here may be attributed to the phylogenetic placement of $A$. triostegus branching off from the clade containing all Acanthurus + Ctenochaetus species but A. thompsoni [38].

These markers are currently being - or will be - used to investigate historical biogeography, population connectivity at various spatial scales, larval recruitment patterns, hybridization, and speciation in reef fishes. 
We thank Christelle Paillon and Laurent Vigliola for sharing Acanthuridae specimens used for crossspecies amplification tests.

\section{Compliance with Ethical Standards:}

Funding: This work was funded by the French National Agency for Research (project IM MODEL@ CORALFISH, grant number ANR 2010 Blanc n 1726).

Ethical approval: Ethical approval was granted for this study by the French Centre National de la Recherche Scientifique (CNRS) under the authorization to handle live animals 006725-1995 and with a research permit provided by the Province Sud of New Caledonia (\#3959-2011/ARR/DENV).

\section{References}

1. Marshell A, Mumby PJ (2015) The role of surgeonfish (Acanthuridae) in maintaining algal turf biomass on coral reefs. J Exp Mar Biol Ecol 473:152-160. https://doi.org/10.1016/j.jembe.2015.09.002

2. Wabnitz C, Taylors M, Green E, Razak T (2003) From ocean to aquarium: the global trade in marine ornamental species. UNEP World Conservation Monitoring Centre, Cambridge, UK

3. Rhyne AL, Tlusty MF, Schofield PJ, et al (2012) Revealing the appetite of the marine aquarium fish trade: the volume and biodiversity of fish imported into the United States. PLOS ONE 7:e35808. https://doi.org/10.1371/journal.pone.0035808

4. Biondo MV (2017) Quantifying the trade in marine ornamental fishes into Switzerland and an estimation of imports from the European Union. Global Ecology and Conservation 11:95-105. https://doi.org/10.1016/j.gecco.2017.05.006

5. Rocha LA, Bass AL, Robertson DR, Bowen BW (2002) Adult habitat preferences, larval dispersal, and the comparative phylogeography of three Atlantic surgeonfishes (Teleostei: Acanthuridae). Mol Ecol 11:243251. https://doi.org/10.1046/j.0962-1083.2001.01431.x

6. Lessios HA, Robertson DR (2006) Crossing the impassable: genetic connections in 20 reef fishes across the eastern Pacific barrier. Proc Biol Sci 273:2201-8. https://doi.org/10.1098/rspb.2006.3543

7. Horne JB, van Herwerden L, Choat JH, Robertson DR (2008) High population connectivity across the Indo-Pacific: Congruent lack of phylogeographic structure in three reef fish congeners. Mol Phyl Evol 49:629-638. https://doi.org/10.1016/j.ympev.2008.08.023

8. Eble JA, Toonen RJ, Bowen BW (2009) Endemism and dispersal: comparative phylogeography of three surgeonfishes across the Hawaiian Archipelago. Mar Biol 156:689-698. https://doi.org/10.1007/s00227008-1119-4 
9. DiBattista JD, Wilcox C, Craig MT, et al (2011) Phylogeography of the Pacific blueline surgeonfish, Acanthurus nigroris, reveals high genetic connectivity and a cryptic endemic species in the Hawaiian archipelago. J Mar Biol 2011:1-17. https://doi.org/10.1155/2011/839134

10. DiBattista JD, Berumen ML, Gaither MR, et al (2013) After continents divide: comparative phylogeography of reef fishes from the Red Sea and Indian Ocean. J Biogeog 40:1170-1181. https://doi.org/10.1111/jbi.12068

11. Selkoe KA, Gaggiotti OE, Bowen BW, Toonen RJ (2014) Emergent patterns of population genetic structure for a coral reef community. Mol Ecol 23:3064-3079. https://doi.org/10.1111/mec.12804

12. Liggins L, Treml EA, Possingham HP, Riginos C (2016) Seascape features, rather than dispersal traits, predict spatial genetic patterns in co-distributed reef fishes. J Biogeog 43:256-267. https://doi.org/10.1111/jbi.12647

13. Otwoma LM, Diemel V, Reuter H, et al (2018) Genetic population structure of the convict surgeonfish Acanthurus triostegus: a phylogeographic reassessment across its range. J Fish Biol 93:597-608. https://doi.org/10.1111/jfb.13686

14. Selkoe KA, Toonen RJ (2006) Microsatellites for ecologists: a practical guide to using and evaluating microsatellite markers. Ecol Lett 9:615-29. https://doi.org/10.1111/j.1461-0248.2006.00889.x

15. Ryman N, Palm S, André C, et al (2006) Power for detecting genetic divergence: differences between statistical methods and marker loci. Mol Ecol 15:2031-2045. https://doi.org/10.1111/j.1365-

294X.2006.02839.x

16. Christie MR, Eble JA (2009) Isolation and characterization of 23 microsatellite loci in the yellow tang, Zebrasoma flavescens (Pisces: Acanthuridae). Mol Ecol Resour 9:544-6. https://doi.org/10.1111/j.17550998.2008.02354.x

17. Eble J, Toonen R, Sorenson L, et al (2011) Escaping paradise: larval export from Hawaii in an IndoPacific reef fish, the yellow tang Zebrasoma flavescens. Mar Ecol Prog Ser 428:245-258. https://doi.org/10.3354/meps09083

18. Christie MR, Tissot BN, Albins MA, et al (2010) Larval connectivity in an effective network of marine protected areas. PLoS One 5:e15715. https://doi.org/10.1371/journal.pone.0015715

19. Horne JB, McIlwain JL, Herwerden L van (2010) Isolation of 15 new polymorphic microsatellite markers from the blue-spine unicornfish Naso unicornis. Conserv Genet Resour 2:191-194. https://doi.org/10.1007/s12686-009-9129-1

20. Horne JB, van Herwerden L, Abellana S, McIlwain JL (2013) Observations of migrant exchange and mixing in a coral reef fish metapopulation link scales of marine population connectivity. J Hered 104:532546. https://doi.org/10.1093/jhered/est021

21. DiBattista JD, Feldheim KA, Bowen BW (2011) Microsatellite DNA markers to resolve population structure and hybridization of two closely related surgeonfish species, Acanthurus nigricans and Acanthurus leucosternon. Conserv Genet Resour 3:159-162. https://doi.org/10.1007/s12686-010-9313-3

22. DiBattista JD, Whitney J, Craig MT, et al (2016) Surgeons and suture zones: Hybridization among four surgeonfish species in the Indo-Pacific with variable evolutionary outcomes. Mol Phyl Evol 101:203-215. https://doi.org/10.1016/j.ympev.2016.04.036

23. Otwoma LM, Reuter H (2019) Do differences in mating behaviour lead to differences in connectivity patterns of reef fishes? Insights from two sympatric surgeonfish species in the Indian Ocean. Mar Environ Res 151:104760. https://doi.org/10.1016/j.marenvres.2019.104760

24. Otwoma LM, Reuter H, Timm J, Meyer A (2018) Genetic connectivity in a herbivorous coral reef fish (Acanthurus leucosternon Bennet, 1833) in the Eastern African region. Hydrobiologia 806:237-250. https://doi.org/10.1007/s10750-017-3363-4 
25. Planes S, Fauvelot C (2002) Isolation by distance and vicariance drive genetic structure of a coral reef fish in the Pacific Ocean. Evolution 56:378-399

26. Schuelke M (2000) An economic method for the fluorescent labeling of PCR fragments. Nat Biotechnol 18:233-234. https://doi.org/10.1038/72708

27. Belkhir K, Borsa P, Chikhi L, et al (1996) GENETIX 4.05, logiciel sous Windows TM pour la génétique des populations. Laboratoire Génome, Populations, Interactions, CNRS UMR 5000, Université de Montpellier II, Montpellier (France).

28. Weir BS, Cockerham CC (1984) Estimating F-Statistics for the analysis of population structure. Evolution 38:1358-1370. https://doi.org/10.2307/2408641

29. Raymond M, Rousset F (1995) GENEPOP (Version 1.2): Population genetics software for exact tests and ecumenicism. J Hered 86:248-249. https://doi.org/10.1093/oxfordjournals.jhered.a111573

30. Rousset F (2008) genepop'007: a complete re-implementation of the genepop software for Windows and Linux. Mol Ecol Resour 8:103-106. https://doi.org/10.1111/j.1471-8286.2007.01931.x

31. Rice WR (1989) Analyzing Tables of Statistical Tests. Evolution 43:223-225. https://doi.org/10.1111/j.1558-5646.1989.tb04220.x

32. Oosterhout CV, Hutchinson WF, Wills DPM, Shipley P (2004) micro-checker: software for identifying and correcting genotyping errors in microsatellite data. Mol Ecol Notes 4:535-538. https://doi.org/10.1111/j.1471-8286.2004.00684.x

33. Jombart T, Devillard S, Balloux F (2010) Discriminant analysis of principal components: a new method for the analysis of genetically structured populations. BMC Genet 11:94. https://doi.org/10.1186/14712156-11-94

34. Jombart T (2008) adegenet: a R package for the multivariate analysis of genetic markers. Bioinformatics 24:1403-1405. https://doi.org/10.1093/bioinformatics/btn129

35. Pritchard JK, Stephens M, Donnelly P (2000) Inference of population structure using multilocus genotype data. Genetics 155:945-959

36. Jakobsson M, Rosenberg NA (2007) CLUMPP: a cluster matching and permutation program for dealing with label switching and multimodality in analysis of population structure. Bioinformatics 23:1801-6. https://doi.org/10.1093/bioinformatics/btm233

37. Rosenberg NA (2004) distruct: a program for the graphical display of population structure. Mol Ecol Notes 4:137-138. https://doi.org/10.1046/j.1471-8286.2003.00566.x 
a.

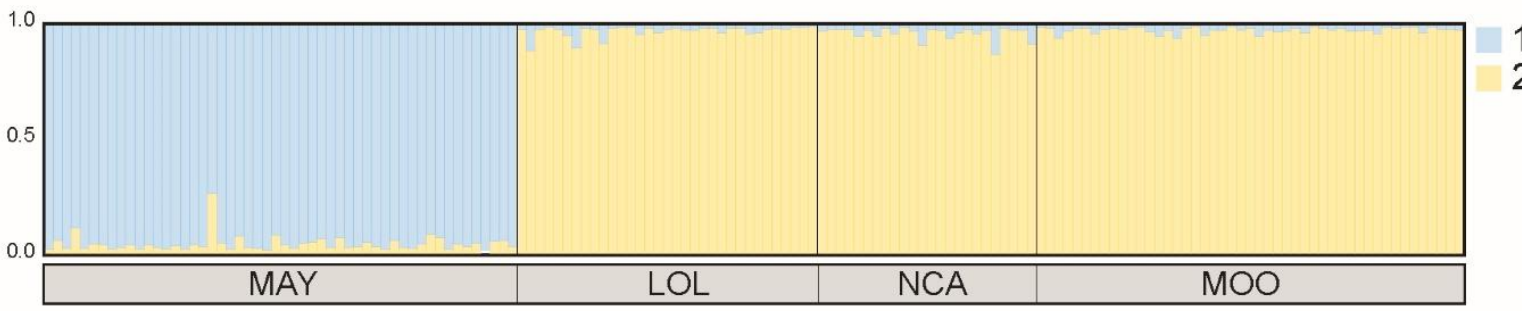

b.
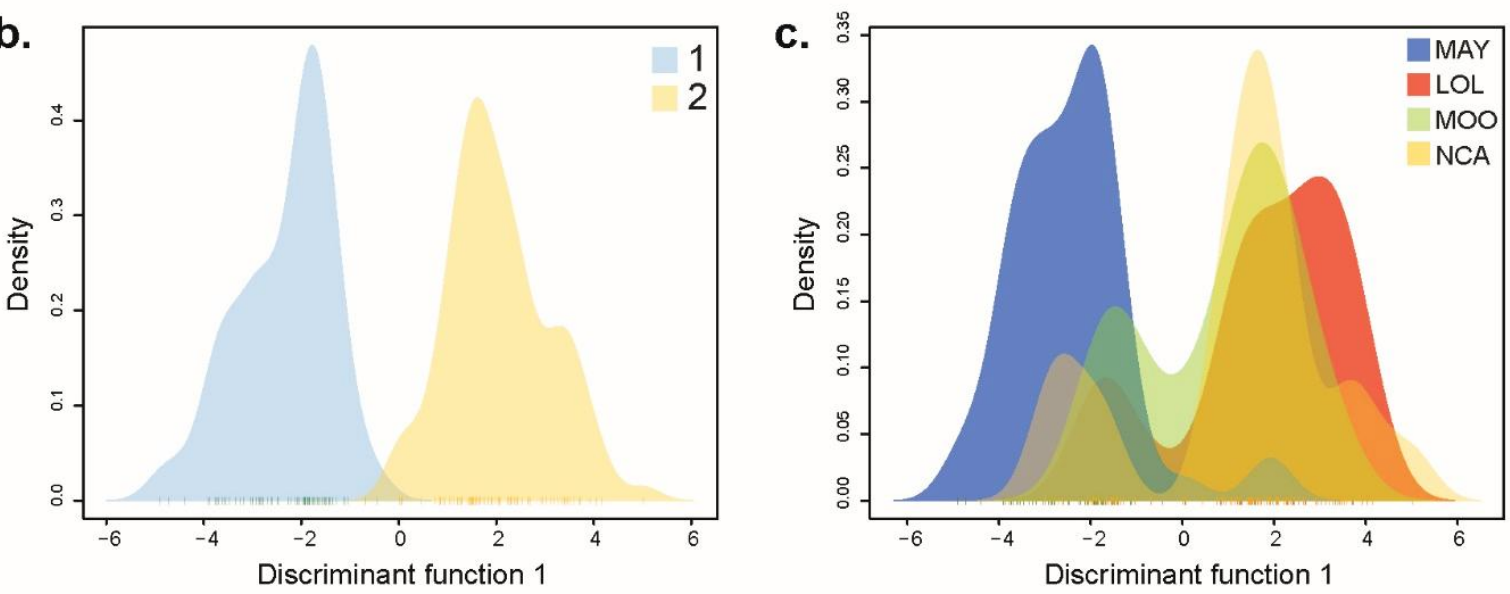

333

Figure 1: Population differentiation of A. triostegus populations based on the analysis of 14 microsatellite loci. STRUCTURE assignment plot showing individual's posterior probabilities of membership to each of the two clusters (a). DAPC scatter plots of the first discriminant function of the Principal Component Analysis (PCA) representing individual densities based on their membership to each cluster (b), or based on their population of origin (c). MAY: Mayotte, south Western Indian Ocean; LOL: Loloata Island, Papua New Guinea; NCA: New Caledonia and MOO: Moorea, French Polynesia. 
Table 1: Characteristics of 14 microsatellite loci isolated in Acanthurus triostegus. Dye = fluorescent dye used for each forward primer, Mix = multiplex in which each loci was amplified. Size: observed amplified fragment size range (in bp). Genetic diversity indexes per loci and over all loci, within each sample (MOO: Moorea; NCA: New Caledonia; LOL: Loloata Island; MAY: Mayotte). $N=$ Number of analyzed individuals; $N a$ : Number of alleles; $H_{E}$ : expected heterozygosity; $H_{O}$ : observed heterozygosity; $F_{I S}$ : Weir \& Cockerham's (1984) inbreeding coefficient. * = significant after standard Bonferroni correction.

\begin{tabular}{|c|c|c|c|c|c|c|c|c|c|c|c|c|c|c|c|c|}
\hline & \multirow[b]{2}{*}{ Primer sequence 5'-3' } & \multirow[b]{2}{*}{$\begin{array}{c}\text { Repeat } \\
\text { array }\end{array}$} & \multirow[b]{2}{*}{ Dye (Mix) } & \multirow[b]{2}{*}{ Size } & \multicolumn{3}{|c|}{$\operatorname{MOO}(N=47)$} & \multicolumn{3}{|c|}{ NCA $(N=24)$} & \multicolumn{3}{|c|}{ LOL $(N=33)$} & \multicolumn{3}{|c|}{ MAY $(N=52)$} \\
\hline & & & & & $\mathrm{Na}$ & $\boldsymbol{H}_{\mathrm{E}} / \boldsymbol{H}_{\mathrm{O}}$ & $F_{I S}$ & $\mathrm{Na}$ & $\boldsymbol{H}_{\mathrm{E}} / \boldsymbol{H}_{\mathrm{O}}$ & $F_{I S}$ & $\mathrm{Na}$ & $\boldsymbol{H}_{\mathrm{E}} / \boldsymbol{H}_{\mathrm{O}}$ & $F_{I S}$ & $\mathrm{Na}$ & $\boldsymbol{H}_{\mathrm{E}} / \boldsymbol{H}_{\mathrm{O}}$ & $F_{I S}$ \\
\hline \multirow[t]{2}{*}{ Acatri_03083 } & F: CATTGAGTCACCGCATCCTG & $(\mathrm{AC})_{13}$ & VIC (2) & $161-199$ & 15 & 0.826 & 0.032 & 10 & 0.827 & 0.114 & 8 & 0.828 & 0.173 & 12 & 0.770 & 0.011 \\
\hline & R: GCTGAGTTCAGAGCATTGGC & & & & & 0.809 & & & 0.750 & & & 0.697 & & & 0.769 & \\
\hline \multirow[t]{2}{*}{ Acatri_04614 } & F: TCAGTGCTGCTGTGAATTGG & $(\mathrm{TG})_{14}$ & $\operatorname{VIC}(1)$ & $134-160$ & 13 & 0.866 & -0.043 & 12 & 0.880 & -0.015 & 10 & 0.846 & 0.012 & 12 & 0.843 & -0.058 \\
\hline & R: CTCATGCACAAACACAAGAC & & & & & 0.913 & & & 0.913 & & & 0.849 & & & 0.900 & \\
\hline \multirow[t]{2}{*}{ Acatri_05455 } & F: ATACGGACACACAAGTGGGC & $(\mathrm{CA})_{14}$ & PET (2) & $83-161$ & 22 & 0.921 & 0.022 & 16 & 0.920 & 0.062 & 18 & 0.905 & 0.011 & 14 & 0.760 & -0.025 \\
\hline & R: AGTTTAATTGGTGGCGATGAC & & & & & 0.911 & & & 0.889 & & & 0.909 & & & 0.787 & \\
\hline \multirow[t]{2}{*}{ Acatri_09735 } & F : TGTCTATTGTTTTGGACAAGGAGC & $(\mathrm{GT})_{18}$ & NED (2) & $98-140$ & 21 & 0.910 & 0.031 & 16 & 0.913 & 0.077 & 20 & 0.912 & 0.085 & 24 & 0.906 & 0.140 \\
\hline & R: TGGTCCAACCTGAGACAGC & & & & & 0.891 & & & 0.864 & & & 0.849 & & & 0.789 & \\
\hline \multirow[t]{2}{*}{ Acatri_09917 } & F: GTGCTCTCAAAGACACAGCC & $(\mathrm{TCTG})_{18}$ & NED (2) & $190-302$ & 20 & 0.925 & 0.137 & 17 & 0.927 & $0.382 *$ & 21 & 0.941 & $0.210^{*}$ & 20 & 0.932 & $0.173^{*}$ \\
\hline & R: CATGCCCCATTCGACAAAAC & & & & & 0.810 & & & 0.591 & & & 0.758 & & & 0.780 & \\
\hline \multirow[t]{2}{*}{ Acatri_10969 } & F: GGAGCAAATACGAGCGAGTG & $(\mathrm{TG})_{15}$ & 6-FAM (2) & $196-218$ & 10 & 0.806 & -0.098 & 12 & 0.870 & 0.159 & 12 & 0.876 & 0.012 & 15 & 0.874 & 0.042 \\
\hline & R: AAGGACGTAGTCAGCACACC & & & & & 0.894 & & & 0.750 & & & 0.879 & & & 0.846 & \\
\hline \multirow[t]{2}{*}{ Acatri_13144 } & F: TCTGTTTAAATGCACAAACGC & $(\mathrm{CA})_{15}$ & 6-FAM (1) & $134-142$ & 5 & 0.692 & 0.175 & 7 & 0.744 & 0.125 & 7 & 0.757 & 0.015 & 10 & 0.769 & 0.041 \\
\hline & R: GTGTGTCTCCAGATCCAGGC & & & & & 0.578 & & & 0.667 & & & 0.758 & & & 0.745 & \\
\hline \multirow[t]{2}{*}{ Acatri_13915 } & F: CAGTCTGCTGAACCTCCTCC & $(\mathrm{AC})_{13}$ & PET (1) & $90-130$ & 13 & 0.829 & $0.523 *$ & 10 & 0.716 & 0.103 & 13 & 0.863 & 0.045 & 22 & 0.919 & $0.237^{*}$ \\
\hline & R: TCGAATCAATCTGTGCGTGC & & & & & 0.409 & & & 0.667 & & & 0.839 & & & 0.711 & \\
\hline \multirow[t]{2}{*}{ Acatri_14579 } & F: ACACCAGCACGTCTAGGAAG & $(\mathrm{CA})_{14}$ & $\operatorname{VIC}(1)$ & $86-120$ & 13 & 0.757 & 0.092 & 10 & 0.804 & -0.067 & 12 & 0.793 & 0.060 & 11 & 0.468 & 0.065 \\
\hline & R: ACTGCTGGATAACAGTGTGTG & & & & & 0.696 & & & 0.875 & & & 0.758 & & & 0.442 & \\
\hline \multirow[t]{2}{*}{ Acatri_15132 } & F: GAGCTTGACCTACATGTGCC & $(\mathrm{TG})_{16}$ & NED (1) & $86-124$ & 11 & 0.791 & -0.028 & 8 & 0.728 & 0.276 & 8 & 0.752 & 0.088 & 11 & 0.745 & 0.080 \\
\hline & R: ATCACTTCTCCTGCGTGGAC & & & & & 0.822 & & & 0.542 & & & 0.697 & & & 0.692 & \\
\hline \multirow[t]{2}{*}{ Acatri_15723 } & F: GGCTAGCTGAGCACATTCAG & $(\mathrm{GT})_{13}$ & 6-FAM (1) & 84-104 & 10 & 0.838 & 0.083 & 8 & 0.823 & 0.059 & 8 & 0.828 & 0.064 & 7 & 0.824 & 0.053 \\
\hline & R: AGCATCGTAGGTATGCGGAG & & & & & 0.778 & & & 0.792 & & & 0.788 & & & 0.789 & \\
\hline \multirow[t]{2}{*}{ Acatri_16496 } & F: ATCCTCTGACAATAGGCCCG & $(\mathrm{GT})_{12}$ & PET (1) & $146-170$ & 10 & 0.817 & 0.066 & 8 & 0.817 & -0.089 & 11 & 0.820 & -0.020 & 14 & 0.867 & 0.012 \\
\hline & R: TGCAGACACTATGTAGTCCACC & & & & & 0.773 & & & 0.909 & & & 0.849 & & & 0.865 & \\
\hline \multirow[t]{2}{*}{ Acatri_17233 } & F: GGGCTCGTTTATCTGCAAGG & $(\mathrm{GT})_{13}$ & NED (1) & $126-166$ & 17 & 0.912 & -0.006 & 11 & 0.891 & 0.183 & 16 & 0.888 & 0.025 & 17 & 0.908 & -0.068 \\
\hline & R: GTAAGTGATCTCGGTTAGATGC & & & & & 0.929 & & & 0.750 & & & 0.879 & & & 0.979 & \\
\hline \multirow[t]{2}{*}{ Acatri_18344 } & F: TCAGCCAGCCGAATCTGAAC & $(\mathrm{TG})_{19}$ & 6-FAM (2) & $106-142$ & 18 & 0.863 & 0.074 & 13 & 0.872 & 0.160 & 17 & 0.893 & 0.167 & 22 & 0.921 & 0.008 \\
\hline & R: CTCACCAAGCCATGTTAGCC & & & & & 0.809 & & & 0.750 & & & 0.758 & & & 0.923 & \\
\hline \multirow[t]{2}{*}{ over all loci } & & & & & 14.14 & 0.840 & & 11.21 & 0.838 & & 12.93 & 0.850 & & 15.07 & 0.822 & \\
\hline & & & & & & 0.787 & & & 0.765 & & & 0.805 & & & 0.787 & \\
\hline
\end{tabular}


Table 2: Cross species amplification of fourteen loci isolated in Acanthurus triostegus tested in thirteen Acanthuridae species. For each species, the total number of individual used is indicated in parenthesis $(\mathrm{n}=)$. Then for each locus, the first number indicates the number of amplified alleles, followed by the number of amplified individuals in parenthesis. Range: range size of the amplified fragments (in base pairs). - : no amplification.

\begin{tabular}{|c|c|c|c|c|c|c|c|c|c|c|c|c|c|c|}
\hline & $\begin{array}{l}\text { Acatri } \\
03083\end{array}$ & $\begin{array}{l}\text { Acatri_ } \\
04614\end{array}$ & $\begin{array}{l}\text { Acatri_ } \\
05455\end{array}$ & $\begin{array}{l}\text { Acatri_ } \\
09735\end{array}$ & $\begin{array}{l}\text { Acatri_ } \\
09917\end{array}$ & $\begin{array}{l}\text { Acatri_ } \\
10969\end{array}$ & $\begin{array}{l}\text { Acatri_ } \\
13144\end{array}$ & $\begin{array}{l}\text { Acatri } \\
13915\end{array}$ & $\begin{array}{l}\text { Acatri } \\
14579\end{array}$ & $\begin{array}{l}\text { Acatri } \\
15132\end{array}$ & $\begin{array}{l}\text { Acatri } \\
15723\end{array}$ & $\begin{array}{l}\text { Acatri } \\
16496\end{array}$ & $\begin{array}{l}\text { Acatri_- } \\
17233\end{array}$ & $\begin{array}{l}\text { Acatri } \\
18344\end{array}$ \\
\hline Aalb $(\mathrm{n}=8)$ & $3(8)$ & - & $2(5)$ & $5(8)$ & - & - & $7(7)$ & - & $3(7)$ & - & - & - & - & $6(8)$ \\
\hline Range & 173-191 & - & $105-107$ & $104-136$ & - & - & $164-212$ & - & $78-84$ & - & - & - & - & $108-124$ \\
\hline $\operatorname{Ablo}(\mathrm{n}=5)$ & $5(5)$ & - & - & $5(4)$ & - & - & - & - & $4(3)$ & - & - & - & - & $3(5)$ \\
\hline Range & $177-187$ & - & - & $90-122$ & - & - & - & - & $90-100$ & - & - & - & - & $104-126$ \\
\hline $\operatorname{Adus}(\mathrm{n}=3)$ & $3(3)$ & - & $4(2)$ & $2(3)$ & - & - & - & - & $2(3)$ & - & - & - & - & $3(3)$ \\
\hline Range & $177-189$ & - & $93-111$ & 104-106 & - & - & - & - & $80-82$ & - & - & - & - & $116-120$ \\
\hline $\operatorname{Anic}(\mathrm{n}=1)$ & $1(1)$ & - & $1(1)$ & $1(1)$ & - & - & $1(1)$ & - & - & - & $1(1)$ & - & - & $1(1)$ \\
\hline Range & 175 & - & 99 & 104 & - & - & 150 & - & - & - & 85 & - & - & 110 \\
\hline $\operatorname{Anif}(n=4)$ & $4(4)$ & - & $1(2)$ & $6(4)$ & - & - & - & - & - & $3(4)$ & $2(4)$ & - & - & $6(4)$ \\
\hline Range & $171-203$ & - & 117 & $92-124$ & - & - & - & - & - & $88-96$ & $86-88$ & - & - & $94-128$ \\
\hline Anig $(\mathrm{n}=8)$ & $3(8)$ & $4(8)$ & $9(7)$ & $9(7)$ & - & $3(6)$ & $7(8)$ & - & - & $4(8)$ & - & $4(8)$ & $2(8)$ & $6(7)$ \\
\hline Range & $173-177$ & $185-195$ & $99-161$ & $90-118$ & - & 194-198 & $162-184$ & - & - & $96-114$ & - & $138-140$ & $128-148$ & $80-94$ \\
\hline $\operatorname{Aoli}(\mathrm{n}=\mathbf{3})$ & $2(3)$ & - & $2(3)$ & $3(3)$ & - & - & $1(1)$ & - & $1(1)$ & - & $2(1)$ & - & - & $3(3)$ \\
\hline Range & $169-177$ & - & $101-103$ & $94-98$ & - & - & 148 & - & 80 & - & $86-96$ & - & - & $106-124$ \\
\hline $\operatorname{Apyr}(\mathrm{n}=8)$ & $6(8)$ & - & $4(8)$ & $4(8)$ & - & - & $6(7)$ & - & $2(5)$ & $6(8)$ & $4(6)$ & - & - & $3(8)$ \\
\hline Range & $173-187$ & - & $95-101$ & 88-94 & - & - & $146-168$ & - & $78-88$ & $84-98$ & $88-94$ & - & - & $80-86$ \\
\hline $\operatorname{Axan}(\mathrm{n}=8)$ & $5(8)$ & $1(4)$ & - & $1(6)$ & - & - & $2(3)$ & - & $5(6)$ & - & $2(5)$ & - & - & $4(7)$ \\
\hline Range & $177-185$ & 176 & - & 102 & - & - & $140-162$ & - & $84-94$ & - & $84-86$ & - & - & $110-120$ \\
\hline $\operatorname{Cbir}(n=1)$ & $2(1)$ & - & $2(1)$ & $2(1)$ & - & - & $1(1)$ & - & - & $1(1)$ & $2(1)$ & - & $1(1)$ & $1(1)$ \\
\hline Range & $169-179$ & - & $97-99$ & $106-110$ & - & - & 144 & - & - & 102 & $84-92$ & - & 132 & 98 \\
\hline Ctfla $(\mathrm{n}=6)$ & $4(6)$ & $5(6)$ & $3(6)$ & $6(6)$ & - & - & - & - & - & $6(6)$ & - & - & - & $6(6)$ \\
\hline Range & $165-179$ & $130-156$ & 93-99 & $92-132$ & - & - & - & - & - & $80-98$ & - & - & - & 88-102 \\
\hline Cstr $(\mathrm{n}=8)$ & $10(8)$ & $1(1)$ & - & $9(8)$ & - & $2(3)$ & 7 (6) & - & $6(5)$ & $4(6)$ & - & - & - & $4(8)$ \\
\hline Range & $165-223$ & 138 & - & $94-120$ & - & $216-220$ & $116-206$ & - & $90-114$ & $94-104$ & - & - & - & $86-94$ \\
\hline Nlit $(\mathrm{n}=8)$ & $3(8)$ & - & - & - & - & - & - & - & - & $2(4)$ & - & - & $4(7)$ & $3(8)$ \\
\hline Range & $175-187$ & - & - & - & - & - & - & - & - & $94-110$ & - & - & $124-140$ & $96-122$ \\
\hline
\end{tabular}


Aalb: Acanthurus albipectoralis; Ablo : Acanthurus blochii; Adus: Acanthurus dussmieri; Anic: Acanthurus nigricauda; Anif: Acanthurus nigrofuscus; Anig : Acanthurus nigricans; Aoli: Acanthurus olivaceus; Apyr : Acanthurus pyroferus; Axan : Acanthurus xanteptorus; Cbir : Ctenochaetus birotatus; Ctfla : Ctenochaetus flavicauda; Cstr : Ctenochaetus striatus; Nlit : Naso lituratus. 